\title{
Development of paroxysmal nocturnal hemoglobinuria in CALR-positive myeloproliferative neoplasm
}

This article was published in the following Dove Press journal: Journal of Blood Medicine

30 May 2016

Number of times this article has been viewed

\author{
Yarden S Fraiman ${ }^{1,2}$ \\ Nathan Cuka ${ }^{3}$ \\ Denise Batista ${ }^{3}$ \\ Milena Vuica-Ross ${ }^{3}$ \\ Alison R Moliterno ${ }^{4}$ \\ 'Department of Pediatrics, Harvard \\ Medical School, ${ }^{2}$ Department of \\ Pediatrics, Boston University School \\ of Medicine, Boston, MA, ${ }^{3}$ Department \\ of Pathology, ${ }^{4}$ Division of Hematology, \\ Department of Medicine, The Johns \\ Hopkins University School of \\ Medicine, Baltimore, MD, USA
}

\begin{abstract}
Paroxysmal nocturnal hemoglobinuria $(\mathrm{PNH})$, a disease characterized by intravascular hemolysis, thrombosis, and bone marrow failure, is associated with mutations in the $P I G-A$ gene, resulting in a deficiency of glycosylphosphatidylinositol-anchored proteins. Many hypotheses have been posed as to whether PNH and $P I G-A$ mutations result in an intrinsic survival benefit of $\mathrm{CD}^{-} 5^{-} / \mathrm{CD} 59^{-}$cells or an extrinsic permissive environment that allows for their clonal expansion within the bone marrow compartment. Recent data have identified the concurrence of $P I G-A$ mutations with additional genetic mutations associated with myeloproliferative disorders, suggesting that some presentations of PNH are the result of a stepwise progression of genetic mutations similar to other myelodysplastic or myeloproliferative syndromes. We report for the first time in the literature the development of clinically significant $\mathrm{PNH}$ in a patient with $J A K 2 \mathrm{~V} 617 \mathrm{~F}$-negative, $C A L R$-positive essential thrombocythemia, providing further support to the hypothesis that the development of PNH is associated with the accumulation of multiple genetic mutations that create an intrinsic survival benefit for clonal expansion. This case study additionally highlights the utility of genomic testing in diagnosis and the understanding of disease progression in the clinical setting.
\end{abstract}

Keywords: calreticulin, myelofibrosis, SNP array, PIGA deletion

\section{Introduction}

Paroxysmal nocturnal hemoglobinuria (PNH) is a disease characterized by intravascular hemolysis, thrombosis, and bone marrow failure. The disease is associated with mutations in the $P I G-A$ gene in hematopoietic stem cells, resulting in a deficiency of glycosylphosphatidylinositol (GPI)-anchored proteins. ${ }^{1}$ This deficiency results in loss of CD55 and CD59, which are believed to be the main GPI-anchored proteins that serve to protect red blood cells (RBCs) from complement-mediated destruction. ${ }^{2}$

This rare disease, estimated at two to five new cases per million US inhabitants, has led to the development of multiple hypotheses that seek to explain the role of $P I G-A$ gene mutations and the survival, and clonal expansion, of CD55-/CD59- cells (PNH cells). ${ }^{1}$ These hypotheses seek to understand whether there is either an extrinsic permissive environment or an intrinsic survival benefit to $\mathrm{PNH}$ cells that allows for the clonal expansion within the bone marrow compartment. ${ }^{1,3,4}$ Additionally, the identification of $\mathrm{CD}^{-} 5^{-} / \mathrm{CD} 59^{-}$cells is not pathognomonic for clinical pathology, as PNH cells have been identified in normal individuals, thus further complicating the understanding of $\mathrm{PNH}$ and the role of $P I G-A .^{5,6}$

While early hypotheses of PNH pathophysiology considered the entity as part of a myelofibrosis (MF)/myelodysplastic syndrome, these conceptualizations largely
Correspondence: Alison R Moliterno Division of Hematology, Department of Medicine, Johns Hopkins University School of Medicine, Traylor 912, 720 Rutland Avenue, Baltimore, MD 21205 , USA

Tel + I 4106146360

Fax +l 410 6140854

Email amoliter@jhmi.edu
Journal of Blood Medicine 2016:7 I07-II0

107

Dovepress

http://dx.doi.org/1 0.2147/JBM.S103473 (c) (i) (5) 2016 Fraiman et al. This work is published and licensed by Dove Medical Press Limited. The full terms of this license are available at https:///www.dovepress.com/terms. (c) ${ }_{\mathrm{BY}} \mathrm{NC}$ php and incorporate the Creative Commons Attribution - Non Commercial (unported, v3.0) License (http://creativecommons.org/licenses/lby-nd $\left./ 3.0 /\right)$. By accessing the work you hereby accept the Terms. Non-commercial uses of the work are permitted without any further permission from Dove Medical Press Limited, provided the work is properly attributed. For

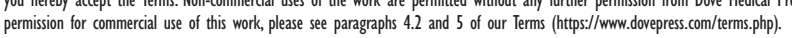


fell out of favor until recently with the advent of new highthroughput genetics and deep sequencing. ${ }^{7}$ Deep sequencing studies have identified acquired somatic mutations in genes associated with myeloid neoplasms not only in hematologic malignancies but also in aging and in nonmalignant hematologic diseases such as aplastic anemia, suggesting that the development of a malignant process is bridged by the acquisition of multiple genetic mutations. ${ }^{8,9}$ Recent data have identified the concurrence of $P I G$ - $A$ mutations with genetic mutations associated with myeloproliferative disorders such as $J A K 2, H M G A 2$, and $B C R-A B L$, thus further supporting the hypothesis that in some occurrences of $\mathrm{PNH}$, the development

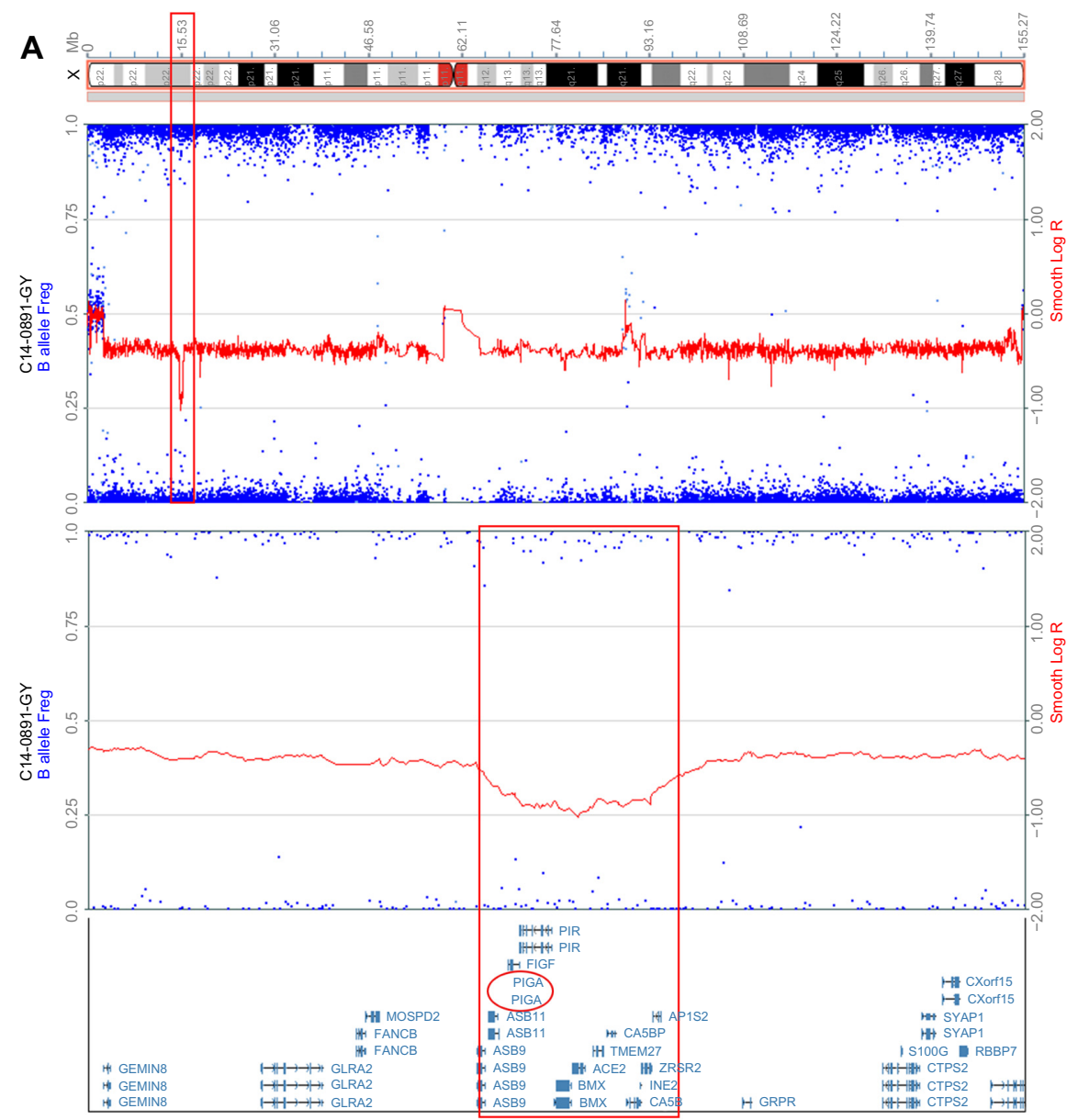

B

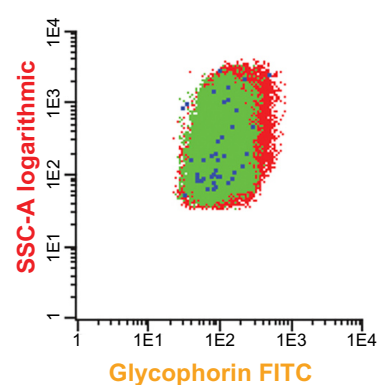

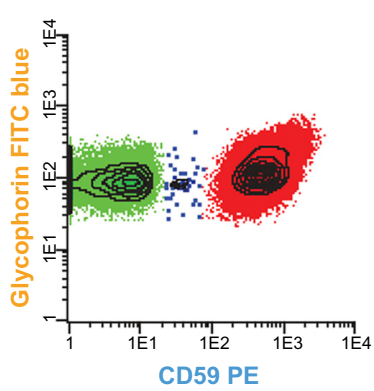

c)

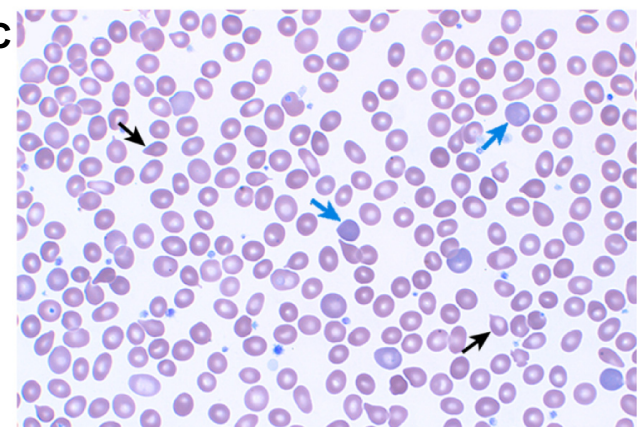

Figure I Molecular and clinical phenotype of PNH in CALR mutation-positive MPN.

Notes: The deletion regions are indicated by the red boxes in the $X$ chromosome cartoon (upper panel A), the SNP array analysis (middle panel A), and the genes mapped to the deletion region including PIG-A (red oval, lower panel A). Flow cytometry of red blood cells indicates loss of CD59 in $16 \%$ of the red cells (green population, panel B). Peripheral blood smear (panel C) is noted for polychromasia, indicating reticulocytosis (blue arrow) characteristic of the hemolysis in PNH and teardrop poikilocytosis (black arrows), indicating extramedullary hematopoiesis characteristic of post-ET MF.

Abbreviations: ET, essential thrombocythemia; FITC, fluorescein isothiocyanate; MF, myelofibrosis; MPN, myeloproliferative neoplasm; PNH, paroxysmal nocturnal hemoglobinuria; SNP array, single-nucleotide polymorphism array; SSC, side scatter; PE, phycoerythrin. 
of clinically significant PNH is the result of a stepwise progression of multiple genetic mutations similar to other myelodysplastic or myeloproliferative syndromes. ${ }^{10-12}$

\section{Myeloproliferative disease evolves to PNH}

Here, we report for the first time in the literature the development of clinically significant $\mathrm{PNH}$ in a patient with $J A K 2$ V617F-negative, CALR-positive essential thrombocythemia (ET). The patient was initially diagnosed with ET in 2005 following the incidental finding of elevated platelets. The patient's initial bone marrow examination was consistent with a myeloproliferative neoplasm (MPN). In 2011 , the patient was noted to have ongoing thrombocytosis (platelets $795 \mathrm{~K} / \mathrm{mm}^{3}$ ) but developed anemia (Hgb $9.0 \mathrm{~g} / \mathrm{dL}$ ), elevated lactate dehydrogenase $(1,440 \mathrm{U} / \mathrm{L})$, and marked reticulocytosis (absolute reticulocyte count $197.3 \mathrm{~K} / \mathrm{mm}^{3}$ ) (Figure 1C). A repeat bone marrow biopsy showed megakaryocyte hyperplasia with myelofibrosis, consistent with post-ET myelofibrosis. The patient had a normal karyotype and a negative $J A K 2 \mathrm{~V} 617 \mathrm{~F}$ mutation but was found to have CALR p.K385fs*47, an acquired somatic mutation strongly associated with the development of MPN. ${ }^{13}$ His hemoglobin improved following iron supplementation, but hemolysis persisted with ongoing elevated lactate dehydrogenase, reduced haptoglobin, and reticulocytosis. Clinically, the patient complained of dyspnea on exertion and tea-colored urine. Urinalysis, which had previously been normal, revealed hemoglobinuria, $56 \mathrm{RBC} / \mu \mathrm{L}$, and $4+$ hemosiderin. High-resolution karyotype with a singlenucleotide polymorphism array revealed hemizygous loss of Xp22.2, an area of the genome that contains the PIG-A gene (Figure 1A). This microdeletion, which has been previously described, is a genetic aberration associated with the development of PNH. ${ }^{14}$ Peripheral blood samples were used for multiparametric flow cytometry analysis based on fluorescent inactive aerolysin and the GPI-anchored proteins CD59 on RBCs and CD14 on monocytes and granulocytes. Flow cytometry identified loss of GPI-anchored proteins (PNH clone) comprising 14\% of RBCs, $60 \%$ of granulocytes, and $73 \%$ of monocytes, thus confirming his diagnosis of PNH (Figure 1B).

\section{Conclusion: insights into pathogenesis of PNH and the utility of genomic testing in the clinic}

Though the development of PNH has been documented to be associated with a number of genetic aberrations associated with MPN and myelodyplasia, this is the first description of the development of PNH in a patient with a CALR mutation. ${ }^{14}$ The progressive quality of his disease, initially from ET to post-ET myelofibrosis with eventual evolution of clinically significant PNH driven by microdeletion of Xp22.2, which encompassed the $P I G-A$ gene, illustrates the evolving nature of myelodysplastic/myeloproliferative conditions and supports the hypothesis that multiple genomic "hits" may occur in order to develop clinically significant PNH. While not fully elucidated, the CALR mutation has been shown to lead to excessive cell proliferation. ${ }^{15}$ We hypothesize that the CALR mutation conferred the survival benefit needed for clonal expansion and survival benefit within the bone marrow stem cell compartment of $P I G-A$ mutant cells, thus cooperating to generate the PNH phenotype.

This case also importantly illustrates the utility of genomic testing outside the research setting and its utility in diagnosis when embedded within the clinical milieu. This patient's normal karyotype coupled with his CALR mutation status allowed for appropriate identification of disease driving lesions and prognostication in ET. As his disease continued to evolve, singlenucleotide polymorphism microarray appropriately identified the etiologic cause of his worsening anemia and changing clinical presentation, thus demonstrating how the clinical availability of sensitive genetic testing leads to more accurate diagnosis, pathogenic understanding of disease process, and the development of more targeted and personalized treatments. ${ }^{16}$

\section{Disclosure}

The authors report no conflicts of interest in this work.

\section{References}

1. Brodsky RA. Paroxysmal nocturnal hemoglobinuria: stem cells and clonality. Hematology Am Soc Hematol Educ Program. 2008;2008(1):111-115.

2. Brodsky RA. Paroxysmal nocturnal hemoglobinuria. Blood. 2014; 124(18):2804-2811.

3. Tiu R, Gondek L, O'Keefe C, Maciejewski JP. Clonality of the stem cell compartment during evolution of myelodysplastic syndromes and other bone marrow failure syndromes. Leukemia. 2007;21(8): $1648-1657$.

4. Maciejewski JP, Sloand EM, Sato T, Anderson S, Young NS. Impaired hematopoiesis in paroxysmal nocturnal hemoglobinuria/aplastic anemia is not associated with a selective proliferative defect in the glycosylphosphatidylinositol-anchored protein-deficient clone. Blood. 1997;89(4):1173-1181.

5. Araten DJ, Nafa K, Pakdeesuwan K, Luzzatto L. Clonal populations of hematopoietic cells with paroxysmal nocturnal hemoglobinuria genotype and phenotype are present in normal individuals. Proc Natl Acad Sci U S A. 1999;96(9):5209-5214.

6. Meletis J, Terpos E, Samarkos M, et al. Detection of CD55 and/or CD59 deficient red cell populations in patients with aplastic anaemia, myelodysplastic syndromes and myeloproliferative disorders. Haematologia (Budap). 2001;31(1):7-16. 
7. Hansen NE, Killmann SA. Paroxysmal nocturnal hemoglobinuria in myelofibrosis. Blood. 1970;36(4):428-431.

8. Yoshizato T, Dumitriu B, Hosokawa K, et al. Somatic mutations and clonal hematopoiesis in aplastic anemia. N Engl J Med. 2015; 373(1):35-47.

9. Xie M, Lu C, Wang J, et al. Age-related mutations associated with clonal hematopoietic expansion and malignancies. Nat Med. 2014;20(12):1472-1478.

10. Shen W, Clemente MJ, Hosono N, et al. Deep sequencing reveals stepwise mutation acquisition in paroxysmal nocturnal hemoglobinuria. J Clin Invest. 2014;124(10):4529-4538.

11. Tominaga R, Katagiri T, Kataoka K, et al. Paroxysmal nocturnal hemoglobinuria induced by the occurrence of BCR-ABL in a PIGA mutant hematopoietic progenitor cell. Leukemia. Epub 2015 Oct 6.

12. Sugimori C, Padron E, Caceres G, et al. Paroxysmal nocturnal hemoglobinuria and concurrent JAK2(V617F) mutation. Blood Cancer J. Epub 2012 Mar 23.
13. Klampfl T, Gisslinger H, Harutyunyan AS, et al. Somatic mutations of calreticulin in myeloproliferative neoplasms. $N$ Engl J Med. 2013;369(25):2379-2390

14. O'Keefe CL, Sugimori C, Afable M, et al. Deletions of Xp22.2 including PIG-A locus lead to paroxysmal nocturnal hemoglobinuria. Leukemia. 2011;25:379-382.

15. Sun C, Zhang S, Li J. Calreticulin gene mutations in myeloproliferative neoplasms without Janus kinase 2 mutations. Leuk Lymphoma. 2015;56(6):1593-1598.

16. Fraiman YS, Moliterno AR. High-density genomic analysis reveals basis of spherocytosis in myelodysplastic syndrome. Blood. 2015; 125(22):3517.

\section{Publish your work in this journal}

The Journal of Blood Medicine is an international, peer-reviewed, open access, online journal publishing laboratory, experimental and clinical aspects of all topics pertaining to blood based medicine including but not limited to: Transfusion Medicine; Blood collection, Donor issues, Transmittable diseases, and Blood banking logistics; Immunohematology; Artificial and alternative

\section{Dovepress}

blood based therapeutics; Hematology; Biotechnology/nanotechnology of blood related medicine; Legal aspects of blood medicine; Historical perspectives. The manuscript management system is completely online and includes a very quick and fair peer-review system. Visit http://www.dovepress.com/ testimonials.php to read real quotes from published authors. 